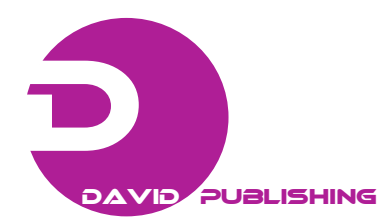

\title{
First Case of ISO22000 Certification in PCO (in Japan)
}

\author{
Hiroshi Yokoyama* and Masataro Suzuki \\ Sato 2-5-11, Naka-ku Hamamatsu-shi, Shizuoka 430-0807, Japan \\ *Corresponding author's e-mail: labo@maruma-ec.co.jp
}

\begin{abstract}
Recently, the levels of consciousness to the food safety of consumers are increasing. It is necessary for the companies engaged in food manufacture to provide safer products in connection with it. ISO22000 is a management system for producing safe foods. In this management system, candidate organizations do not limit to the companies which manufacture food directly, but are taking in broadly to the food chain "farm-to-fork" from growing, harvesting, storage, processing, manufacturing, and distributing food for consumption. Authors prevent and exterminate the insect pests and the harmful animals as a pest control contractor. However, authors aim "comprehensive environmental control" and authors try to prevent of the food poisoning by the microbiological control which is the true purpose of pest control in the food manufacture. For the reason, authors have the service goods, pest control, food inspection, water quality inspection, feces examination, and consulting service (sanitary training program etc.). Authors received ISO22000 certification in a pest control and in a part of food inspection, in connection with the insect fauna investigation which is identification and the countermeasure proposal of the insect captured on the traps, with the prevention and extermination of the insect pests and the harmful animals, and with sanitary diagnosis which is based on check of the food manufacturing environment (microbiological testing for the food and the environment, check of equipment and apparatus, the management state of $5 \mathrm{~S}$ ). The harm factors, called the hazard, to the food in each process of our operation were extracted, and the countermeasures were made. In ISO22000, CCPs (critical control point) and O-PRPs (operation-PRP) are set up. However, authors make sanitary environment rather than food. Therefore, there is no CCP in our system and authors decided to manage a hazard only by O-PRP.
\end{abstract}

Key words: ISO22000 certification, critical control point, hazard, operation-PRP, Japan. 